\title{
Diagnostic value of neutrophil CD64, procalcitonin, and interleukin-6 in sepsis: a meta-analysis
}

\author{
Shan Cong, Tiangang Ma, Xin Di, Chang Tian, Min Zhao and Ke Wang*
}

\begin{abstract}
Background: The aim of the study was to conduct a meta-analysis to evaluate the accuracy of neutrophil CD64, procalcitonin (PCT), and interleukin-6 (IL-6) as markers for the diagnosis of sepsis in adult patients.

Methods: Various databases were searched to collect published studies on the diagnosis of sepsis in adult patients using neutrophil CD64, PCT, and IL-6 levels. Utilizing the Stata SE 15.0 software, forest plots and the area under the summary receiver operating characteristic curves were drawn. The pooled sensitivity, specificity, positive likelihood ratio, negative likelihood ratio, diagnostic odds ratio, and area under the curve (AUC) were calculated.

Results: Fifty-four articles were included in the study. The pooled sensitivity, specificity, and AUC of neutrophil CD64 for the diagnosis of sepsis were 0.88 (95\% confidence interval [Cl], 0.81-0.92), 0.88 (95\% Cl, 0.83-0.91), and 0.94 ( $95 \% \mathrm{Cl}, 0.91-0.96)$, respectively. The pooled sensitivity, specificity, and AUC of PCT for the diagnosis of sepsis were 0.82 (95\% Cl, 0.78-0.85), 0.78 ( $95 \% \mathrm{Cl}, 0.74-0.82)$, and 0.87 (95\% Cl, 0.83-0.89), respectively. Subgroup analysis showed that the AUC for PCT diagnosis of intensive care unit (ICU) sepsis was 0.86 ( $95 \% \mathrm{Cl}, 0.83-0.89$ ) and the AUC for PCT diagnosis of non-ICU sepsis was $0.82(95 \% \mathrm{Cl}, 0.78-0.85)$. The pooled sensitivity, specificity, and AUC of IL- 6 for the diagnosis of sepsis were $0.72(95 \% \mathrm{Cl}, 0.65-0.78), 0.70(95 \% \mathrm{Cl}, 0.62-0.76)$, and $0.77(95 \% \mathrm{Cl}, 0.73-0.80)$, respectively.

Conclusions: Of the three biomarkers studied, neutrophil CD64 showed the highest diagnostic value for sepsis, followed by PCT, and IL-6. On the other hand, PCT showed a better diagnostic potential for the diagnosis of sepsis in patients with severe conditions compared with that in patients with non-severe conditions.
\end{abstract}

Keywords: Sepsis, Neutrophil CD64, Procalcitonin, Interleukin-6, Meta-analysis

\section{Background}

In recent years, the incidence and mortality of sepsis have increased significantly due to the increase of drugresistant bacteria, the widespread use of antibiotics, and the aging of the population. The latest epidemiological study, including septicemia cases in 195 countries around the world, showed that in 2017 there were 48.9 million

\footnotetext{
* Correspondence: wke@jlu.edu.cn

Department of Respiratory Medicine, The Second Hospital of Jilin University, 218 Ziqiang Street, Nanguan District, Changchun 130041, Jilin Province, China
}

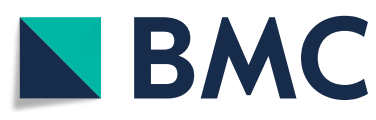

(๑) The Author(s). 2021 Open Access This article is licensed under a Creative Commons Attribution 4.0 International License, which permits use, sharing, adaptation, distribution and reproduction in any medium or format, as long as you give appropriate credit to the original author(s) and the source, provide a link to the Creative Commons licence, and indicate if changes were made. The images or other third party material in this article are included in the article's Creative Commons licence, unless indicated otherwise in a credit line to the material. If material is not included in the article's Creative Commons licence and your intended use is not permitted by statutory regulation or exceeds the permitted use, you will need to obtain permission directly from the copyright holder. To view a copy of this licence, visit http://creativecommons.org/licenses/by/4.0/. The Creative Commons Public Domain Dedication waiver (http://creativecommons.org/publicdomain/zero/1.0/) applies to the data made available in this article, unless otherwise stated in a credit line to the data. sepsis patients and 11 million deaths from sepsis worldwide, which was equivalent to $19.7 \%$ of total deaths throughout the year [1]. In 2016, the Society of Critical Care Medicine (SCCM) and the European Society of Intensive Care Medicine (ESICM) jointly issued the definition of Sepsis 3.0 as the life-threatening organ dysfunction caused by dysregulation of the host's response to infection [2]. At the same time, the diagnostic criteria for sepsis were proposed. For patients with ICU infection or suspected infection, sepsis is diagnosed when the sequential organ failure assessment (SOFA) score is $\geq 2$ [3]. However, 
considering the limitations of the diagnostic criteria and the lack of clinically relevant data in many patients, a simplified method was proposed, named "quick SOFA", (also known as "qSOFA"), that includes a systolic blood pressure $\leq 100 \mathrm{mmHg}$, a respiratory frequency $\geq 22$ times/min, or change of consciousness. When there are two or more score exceptions, this can be considered a high-risk sepsis population [4]. However, Williams et al. [5] found that although qSOFA score was highly specific, its sensitivity was poor, which might not be suitable for early diagnosis of sepsis. Although blood culture is an important tool for sepsis diagnosis that identifies pathogenic bacteria and allows antibiotic susceptibility testing, it is a timeconsuming protocol and has a high false-negative rate, especially after antibiotic use [6]. Therefore, the blood culture alone is not enough to assist clinicians to make accurate early diagnosis in patients with sepsis. According to statistics, if sepsis patients can be correctly diagnosed and treated within $1 \mathrm{~h}$ of infection, their survival rate will reach more than $80 \%$, whereas if patients are diagnosed and treated after $6 \mathrm{~h}$ of infection, their survival rate drops to $30 \%$ [7]. Therefore, it is crucial to find a biomarker for the early diagnosis of sepsis.

Neutrophil CD64 is a high-affinity receptor for the Fc portion of IgG. Neutrophil CD64 is a member of the immunoglobulin superfamily and is mainly found on the surface of antigen-presenting cells, such as monocytes, macrophages, and dendritic cells. When the body is infected, or a large number of bacterial endotoxins are present, neutrophils are exposed to lipopolysaccharides (LPS), complement system molecules, IL-8, IL-12, IFN$\gamma$, TNF- $\alpha$, granulocyte colony-stimulating factor, and other cytokines. Such molecules stimulate the expression of CD64 and it remains stable for a certain period of time [8]. Although neutrophil CD64 expression is low on resting neutrophils, once activated by stimulating factors its expression increases rapidly up to10-fold, reaching a peak within 4 to $6 \mathrm{~h}$. Basal expression is restored 7 days after the stimulation disappears [9]. Neutrophil CD64 is relatively stable in blood samples studied in vitro and is easily detected by flow cytometry. The stable characteristics of neutrophil CD64 make it suitable as a diagnostic indicator.

Biomarkers procalcitonin (PCT) and interleukin-6 (IL6) have been widely used in the diagnosis and identification of infections. Under normal physiological conditions, PCT is produced almost exclusively in thyroid $\mathrm{C}$ cells. Induced by the stimulation of glucocorticoids, calcitonin gene-related peptide, glucagon, gastrin, or $\beta$ adrenergic signaling, PCT is converted into calcitonin before entering the circulatory system. Healthy individuals usually show very low levels of serum PCT $(<0.02$ $\mathrm{ng} / \mathrm{mL}$ ). PCT is a very stable protein in vitro and in vivo, with a half-life of about 20-24 h [10, 11]. Patients with infections can produce PCT through an alternative pathway in non-thyroid tissue. There are two main alternative pathways: the direct pathway, induced by LPS or other toxic microbial metabolites, and the indirect pathway, induced by several inflammatory mediators such as IL-6 and TNF- $\alpha$ [12]. Due to the lack of pathways to convert PCT to calcitonin, PCT enters the circulatory system and its levels can rapidly increase more than 400 -fold (> $4.0 \mathrm{ng} / \mathrm{mL}$ ) compared to basal levels [13].

IL-6 is an important pro-inflammatory factor in the initial stage of inflammation. It induces multiple cells to synthesize and secrete acute phase proteins, promotes the production and activation of neutrophils during infection, promotes the proliferation and differentiation of $\mathrm{B}$ cells, produces immunity globulins, and promotes $\mathrm{T}$ cell proliferation and differentiation [14]. The levels of IL-6 in healthy people are extremely low, generally not exceeding $7 \mathrm{pg} / \mathrm{mL}$, whereas the levels of IL- 6 in the serum of sepsis patients increases rapidly in the early stage of infection, and can reach a peak within $2 \mathrm{~h}$ [15].

The aim of our study was to integrate the results of clinical studies to compare the diagnostic accuracy of neutrophil CD64, PCT, and IL-6 for sepsis in adult patients by meta-analysis.

\section{Materials and methods \\ Study selection}

The articles were manually retrieved from PubMed, Web of Science, Medline, The Cochrane Library, Wan Fang, China Biology Medicine, China National Knowledge Infrastructure, and VIP databases, by searching all publications from the earliest entries to December 2018. Languages were English and Chinese. Firstly, the studies were chosen based on the following subject terms: sepsis, neutrophil CD64, procalcitonin, Interleukin-6, and diagnosis. Then, a relevant-free terms search was carried out, and finally, the two search strategies were combined. Additionally, the references cited in the retrieved articles were also manually retrieved as supplements. Endnote version X7.8 was used for reference management. Two researchers carried out the same search independently, and in case of disagreement, a third researcher was involved to discuss the results and reach an agreement.

\section{Inclusion and exclusion criteria Inclusion criteria}

1. Studies focused on the diagnostic value of neutrophil CD64, PCT, and IL-6 for sepsis; 2. The observation group included adult sepsis patients, aged $\geq 18$ years, whereas the control group included patients or healthy people assessed during the same period; 3.The diagnostic criteria included the clinical diagnostic and or blood culture. The clinical diagnostic criteria were Sepsis 1.0, 
Sepsis 2.0, and Sepsis 3.0; 4. Prospective or retrospective studies; 5 . True positive (TP), false positive (FP), true negative (TN), or false negative (FN) results for neutrophil CD64, PCT, and IL-6 in the diagnosis of sepsis could be obtained directly or calculated from the data.

\section{Exclusion criteria}

1. Abstracts, conference reports, summaries, and comments; 2. TP, FP, TN, and FN cannot be obtained according to the reported data; 3. Repeated research subjects.

\section{Quality assessment}

We used the diagnostic test system evaluation tool Quality Assessment for Diagnostic Accuracy Studies version 2 (QUADAS-2) from the Review Manager 5.3 software to assess the quality of all included articles. The QUADAS-2 scale includes four parts: case selection, trial to be evaluated, gold standard, and case process and progress.

\section{Data extraction}

The research data extraction was independently completed by two researchers. If the extraction results of the two were inconsistent, the third researcher and the first two jointly studied and decided. The data extraction information included the first author, publication date, country, study design, diagnostic criteria, clinical setting, sample size, average age, test method, TP, FP, FN, TN, sensitivity, and specificity.

\section{Statistical analysis}

This study was a diagnostic meta-analysis. The heterogeneity of the included articles was determined to select the appropriate statistical model to help reduce errors during data merging. The heterogeneity between the included studies was evaluated by calculating the chisquare test value and the $\mathrm{I}^{2}$ statistics. If the $\mathrm{I}^{2} \leq 50 \%, P \geq$ 0.05 , the heterogeneity of the included studies was deemed small, and the fixed effect model was used to merge the statistical data. If the $\mathrm{I}^{2}>50 \%, P<0.05$, the heterogeneity was significant, and data were merged by the random effect model. The indexes included

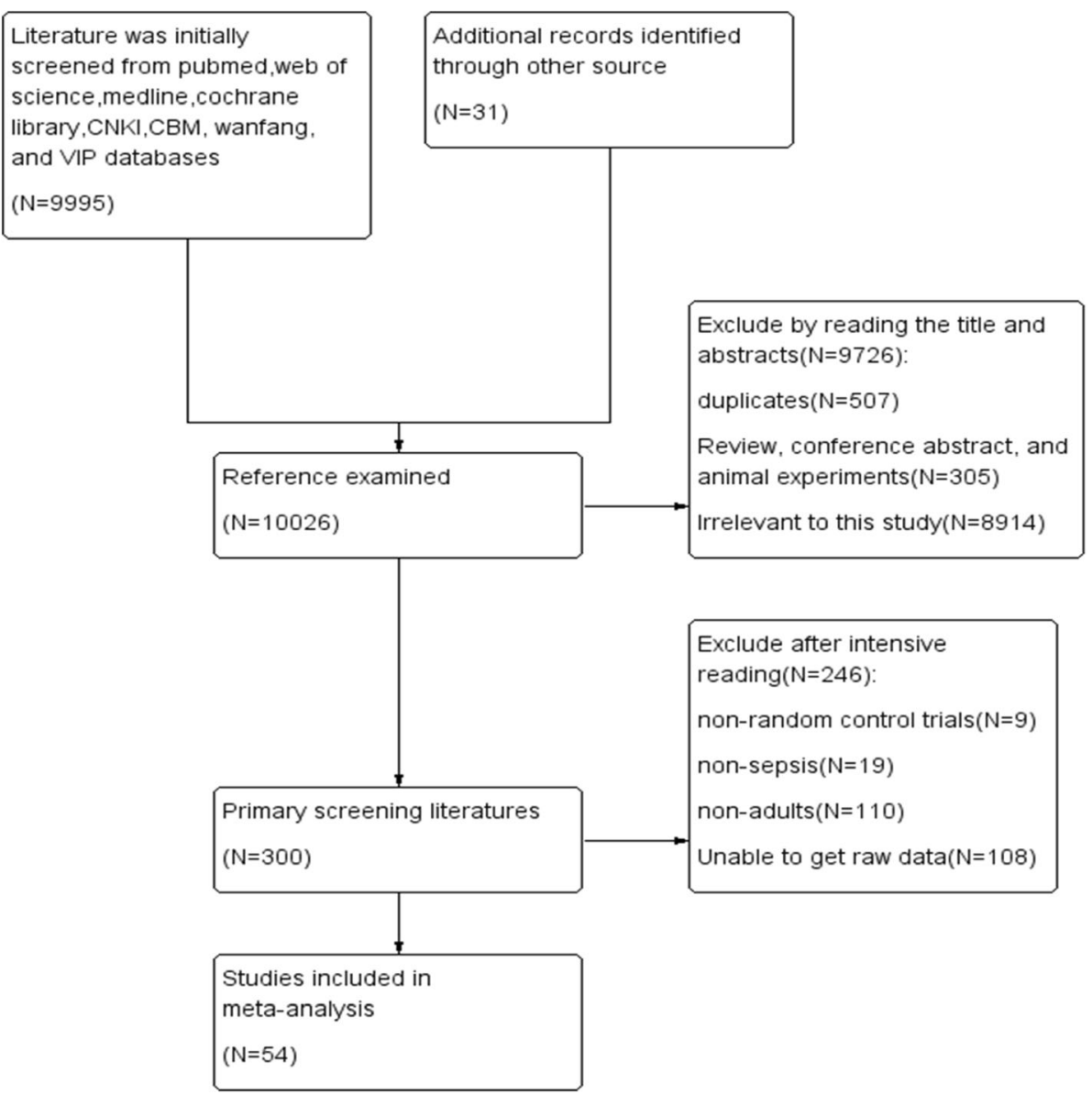

Fig. 1 PRISMA flow diagram of the search strategy and study selection process 


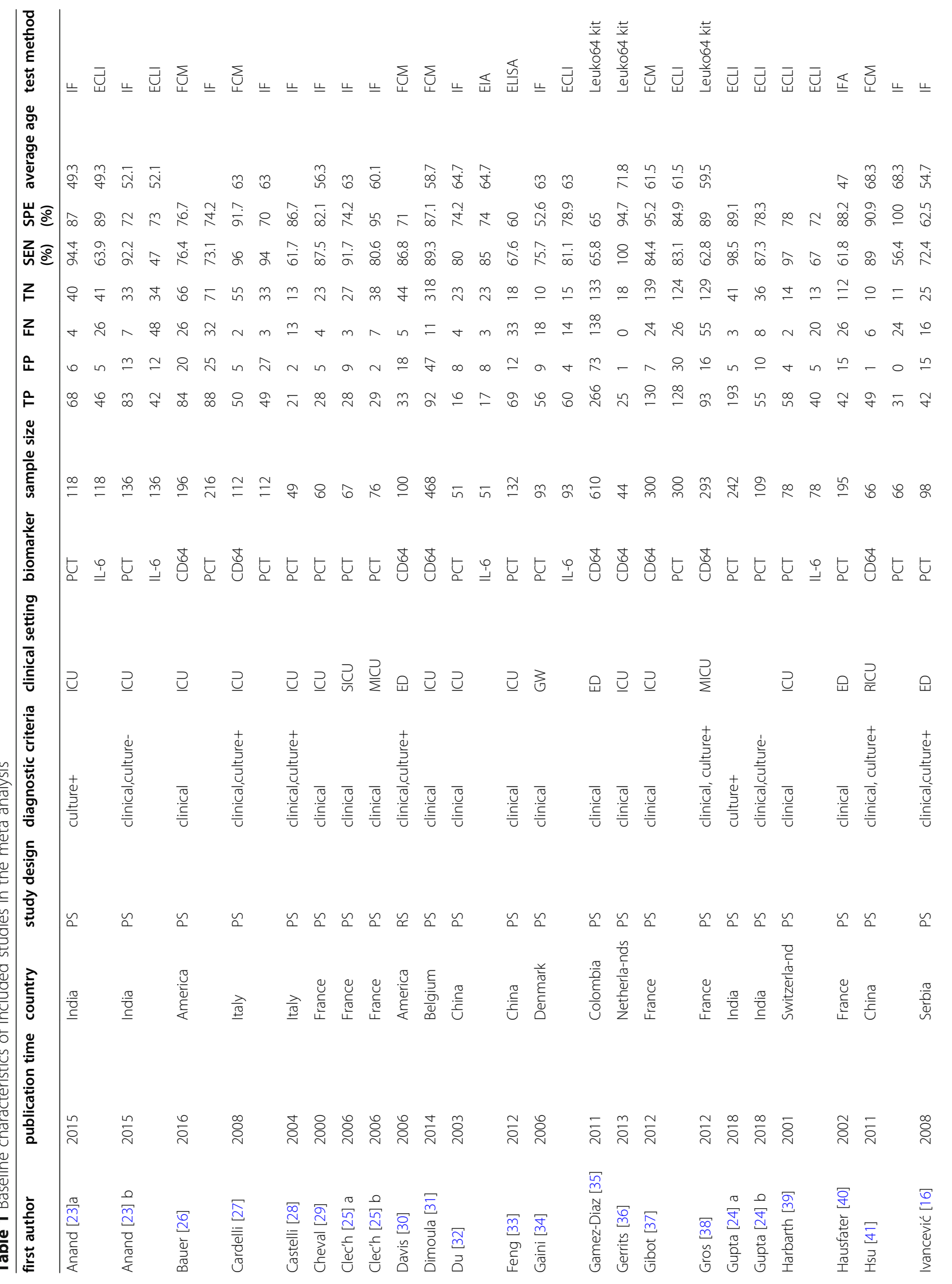




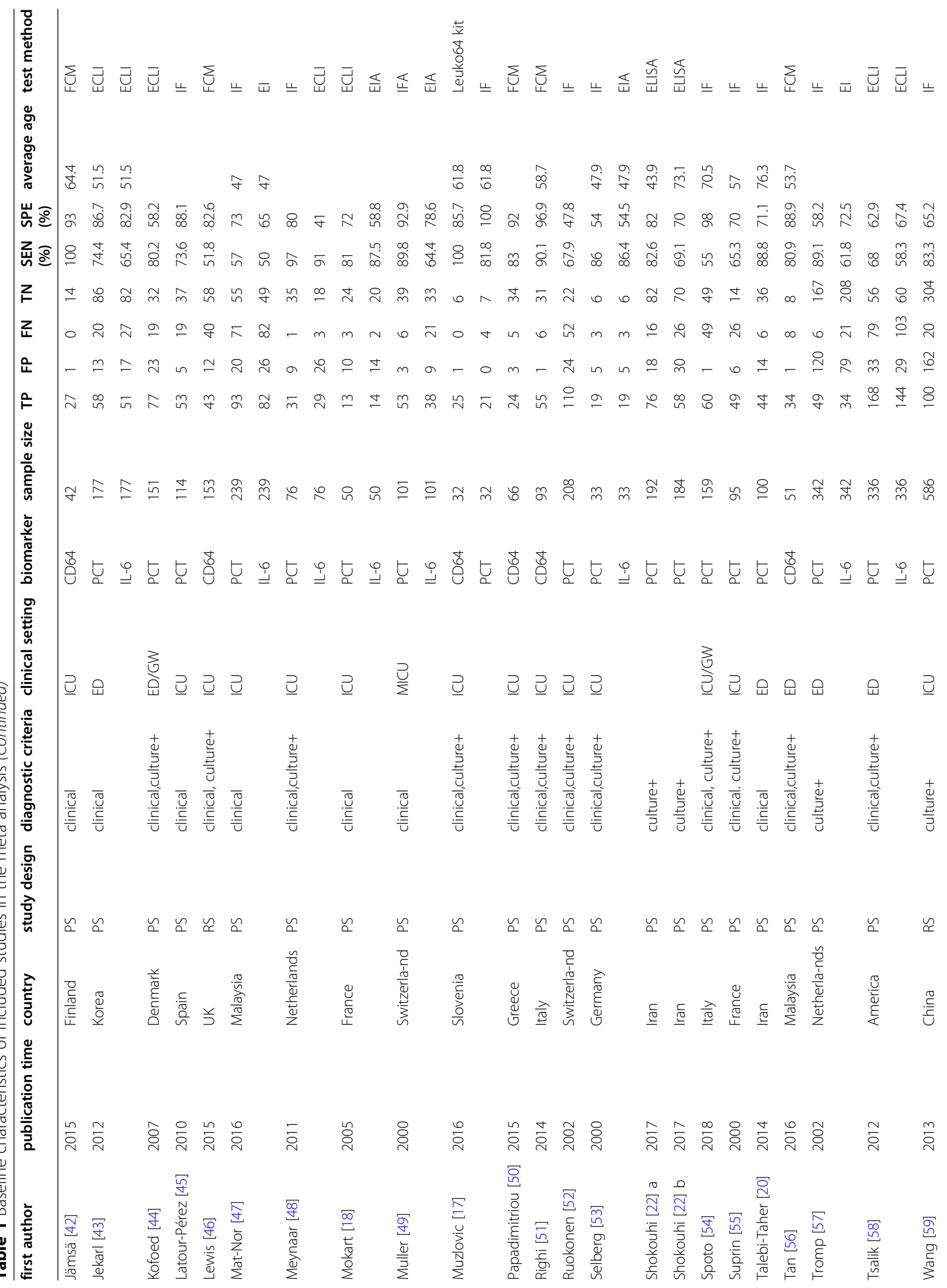




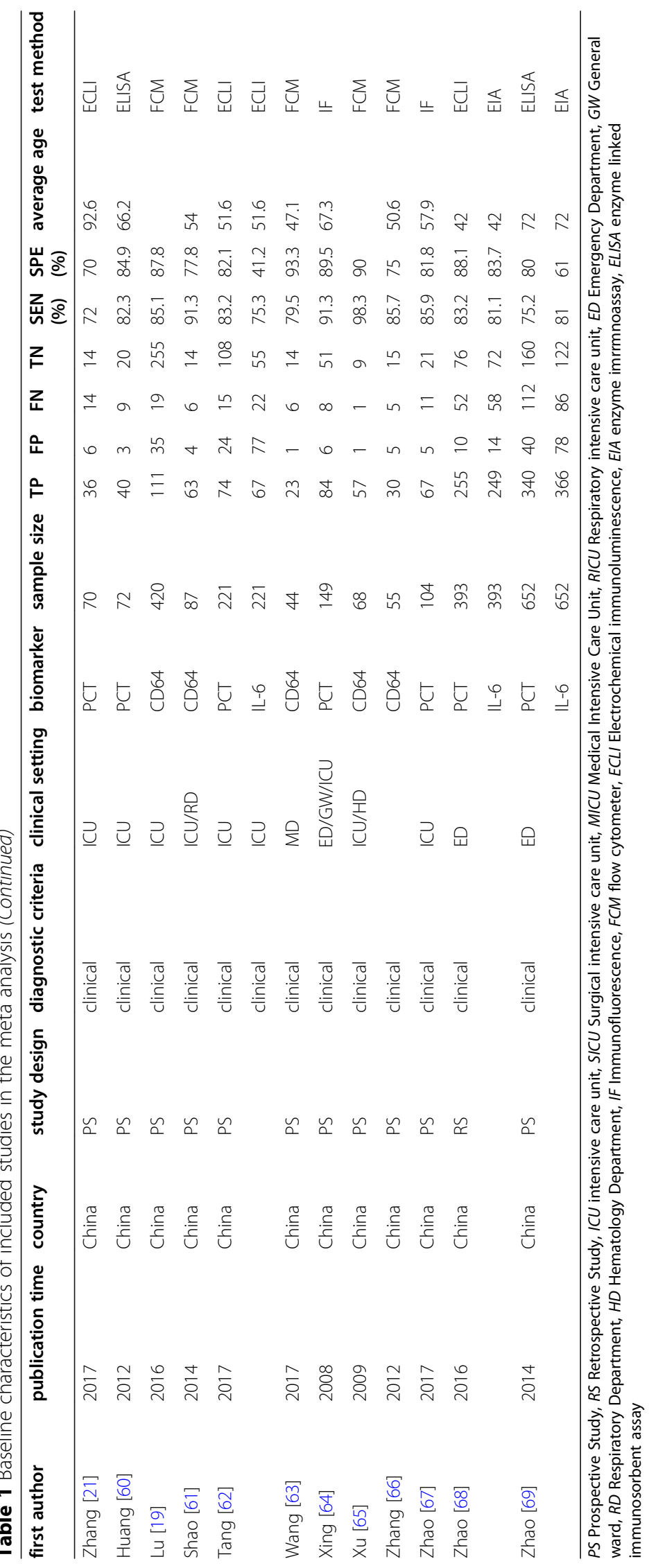




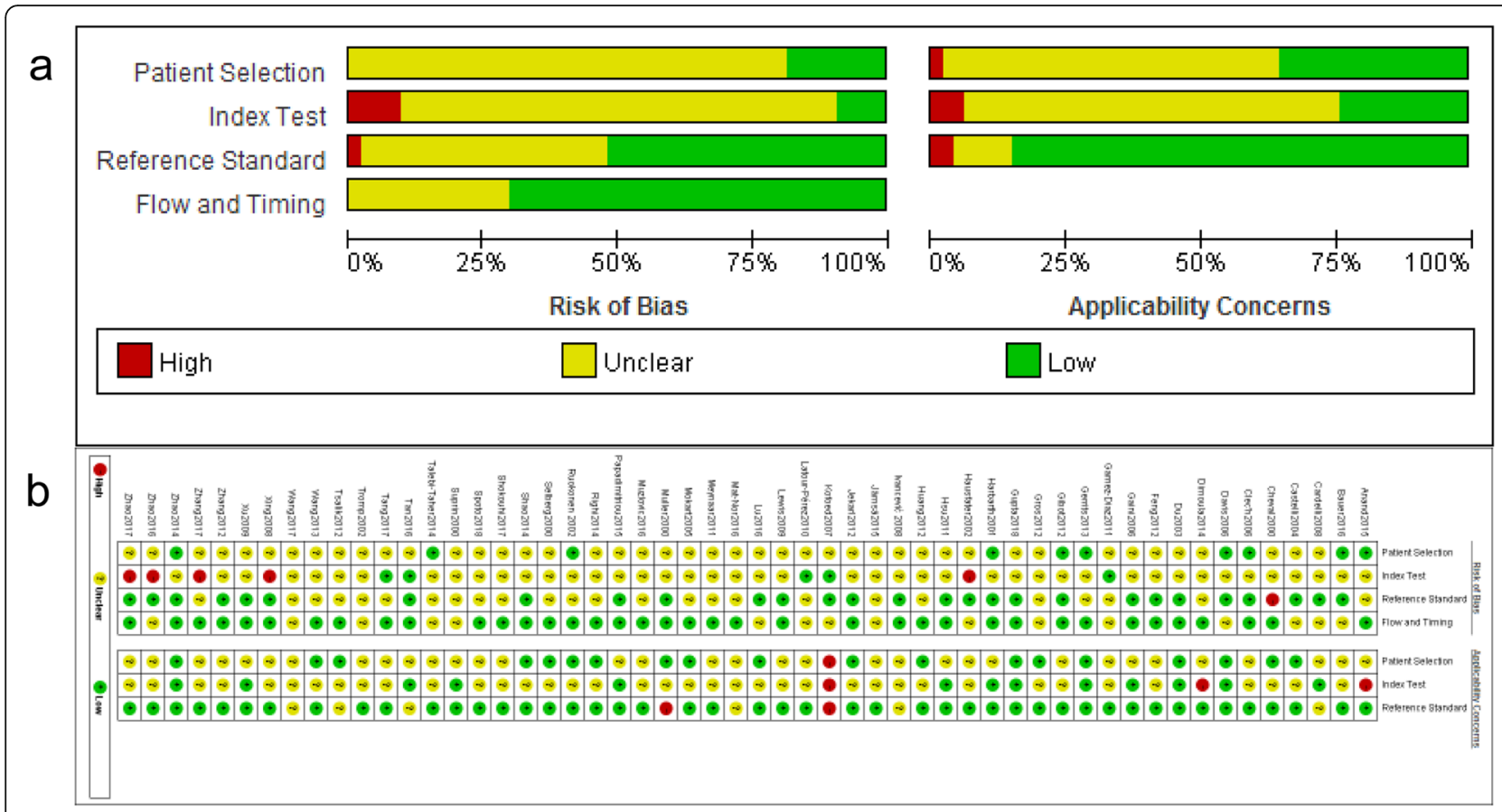

Fig. 2 a Risk of bias. b Clinical applicability

sensitivity, specificity, positive likelihood ratio (PLR), negative likelihood ratio (NLR), and diagnostic odds ratio (DOR). Additionally, a summary receiver operating characteristic (SROC) curve was drawn to calculate the area under the curve (AUC). The closer the AUC value was to 1 , the higher the clinical diagnostic efficacy of this index was. The Deeks' test was used to assess publication bias in the included articles. We used metaregression, sensitivity analysis, and subgroup analysis to explore the sources of heterogeneity. We used Fagan's nomogram to evaluate the post-test probabilities of the three studied biomarkers in sepsis. MetaDisc 1.4 software and STATA 12.0 were used for data analysis.

\section{Results}

\section{Literature search}

In all, 10,026 articles in Chinese and English were retrieved through the preliminary screening of the databases. After reading the titles and abstracts, 300 articles were selected. Intensive reading was performed following strictly the inclusion and exclusion criteria. After the

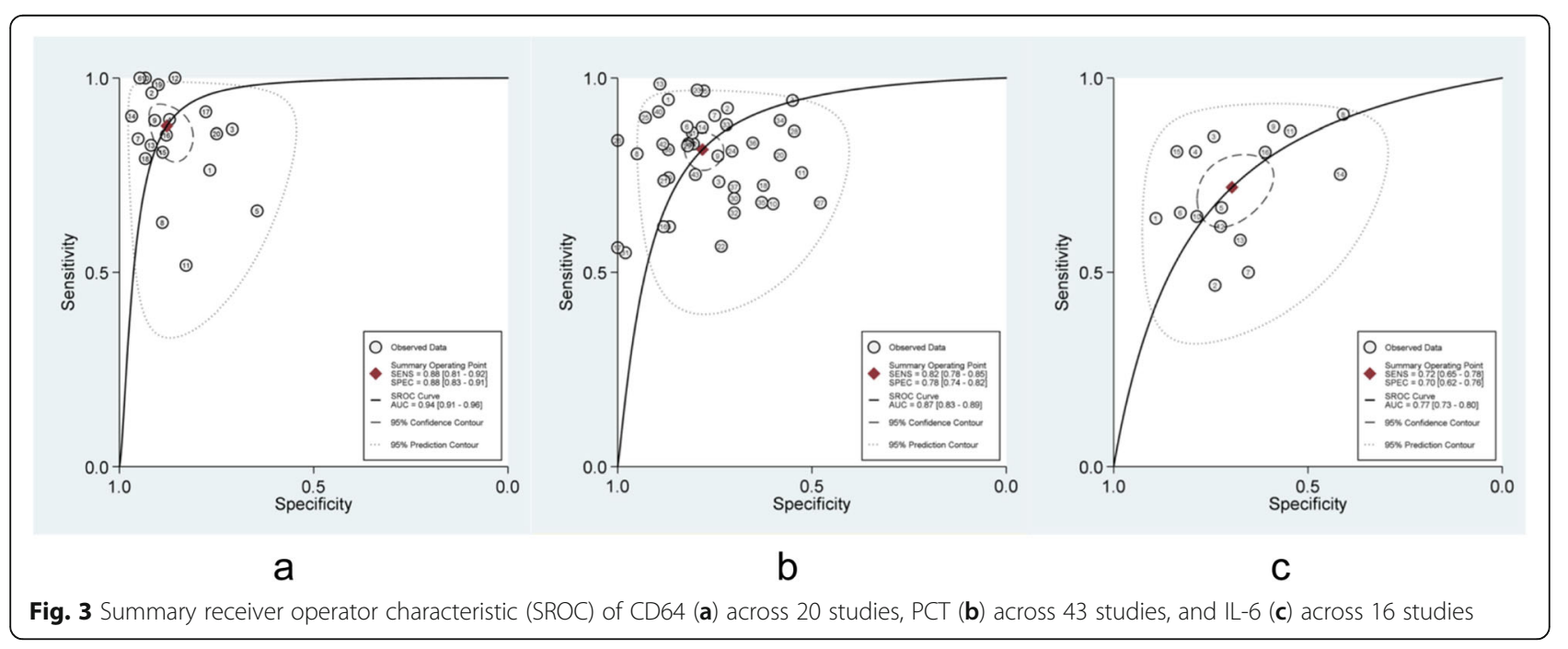


screening, a set of 54 articles were included in the study (Fig. 1).

\section{Study characteristics}

In all, 9842 participants were finally enrolled in this meta-analysis, with a sepsis prevalence of $54.8 \%$. It included 20 studies related to neutrophil CD64, 39 studies related to PCT, and 15 studies related to IL-6. We found 37 articles that reported the average age of the study subjects, ranging from 42.0 to 92.6 years. Four papers focused on patients with specific sepsis, such as patients with acute abdominal sepsis [16], ventilator-associated pneumonia [17], and postoperative sepsis $[18,19]$. Two articles addressed elderly patients with sepsis (aged $>65$ [20] and $>85$ years [21]), whereas another study [22] included patients aged $\leq 65$ and $>65$ years. Two studies $[23,24]$ reported separately cases of positive and negative blood cultures. One paper [25] included a study conducted in the medical ICU and surgical ICU patients. The detailed baseline characteristics of the included studies are summarized in Table 1.

\section{Quality assessment}

We used the QUADAS-2 scale to evaluate the quality of the included articles. The results showed that all studies were of high quality and had clinical practicability (Fig. 2).

\section{Heterogeneity test}

Spearman correlation coefficients of neutrophil CD64, PCT, and IL-6 were $-0.22(P=0.35),-0.054(P=0.729$, $)$ and $0.326(P=0.217)$, respectively. The SROC curve of the three biomarkers did not show a significant shoulder-arm effect, suggesting that there was no threshold effect (Fig. 3).

\section{Pooled effect size result}

Of all included articles, 20 of them reported the diagnostic value of neutrophil CD64 for sepsis. The results for these studies were: pooled sensitivity, 0.88 (95\% CI, 0.81-0.92); pooled specificity, 0.88 (95\% CI, 0.83-0.91) (Fig. 4); pooled PLR, 7.2 (95\% CI, 5.0-10.3); pooled NLR, 0.14 (95\% CI, 0.09-0.22); pooled DOR, 51 (95\% CI, 25-105); and the AUC was 0.94 (95\% CI, 0.91-0.96) (Fig. 3a). Thirty-nine

\begin{tabular}{|c|c|c|c|c|c|}
\hline Studyld & & SENSITIVITY $(95 \% \mathrm{CI})$ & Studyld & & SPECIFICITY $(95 \% \mathrm{CI})$ \\
\hline Zhang2012 & - & $0.86[0.70-0.95]$ & Zhang2012 & -1 & $0.75[0.51-0.91]$ \\
\hline Xu2009 & $i^{\cdot}$ & $0.98[0.91-1.00]$ & Xu2009 & - & $0.90[0.55-1.00]$ \\
\hline Wang2017 & $-\bullet$ & $0.79[0.60-0.92]$ & Wang2017 & - & $0.93[0.68-1.00]$ \\
\hline Shao2014 & $\stackrel{1}{\bullet}$ & $0.91[0.82-0.97]$ & Shao2014 & $-\bullet+1$ & $0.78[0.52-0.94]$ \\
\hline Lu2016 & $\dot{1}$ & $0.85[0.78-0.91]$ & Lu2016 & $\dot{i}$ & $0.88[0.84-0.91]$ \\
\hline $\operatorname{Tan} 2016$ & -0 & $0.81[0.66-0.91]$ & Tan2016 & - & $0.89[0.52-1.00]$ \\
\hline Righi2014 & $\rightarrow$ & $0.90[0.80-0.96]$ & Righi2014 & $T^{\bullet}$ & $0.97[0.84-1.00]$ \\
\hline Papadimitriou2015 & $-0-$ & $0.83[0.64-0.94]$ & Papadimitriou2015 & -6 & $0.92[0.78-0.98]$ \\
\hline Muzlovic2016 & $+\bullet$ & $1.00[0.86-1.00]$ & Muzlovic2016 & - & $0.86[0.42-1.00]$ \\
\hline Lewis2015 & $-\bullet \quad \mid$ & $0.52[0.41-0.63]$ & Lewis2015 & -1 & $0.83[0.72-0.91]$ \\
\hline Jämsä2015 & L• & $1.00[0.87-1.00]$ & Jämsä2015 & - & $0.93[0.68-1.00]$ \\
\hline Hsu2011 & $\stackrel{1}{-}$ & $0.89[0.78-0.96]$ & Hsu2011 & - & $0.91[0.59-1.00]$ \\
\hline Gros2012 & $\cdot 1$ & $0.63[0.55-0.71]$ & Gros2012 & $\vdots$ & $0.89[0.83-0.94]$ \\
\hline Gibot2012 & $\bullet$ & $0.84[0.78-0.90]$ & Gibot2012 & !. & $0.95[0.90-0.98]$ \\
\hline Gerrits2013 & $+\bullet$ & $1.00[0.86-1.00]$ & Gerrits2013 & $\rightarrow$ & $0.95[0.74-1.00]$ \\
\hline Gamez-Diaz2011 & $\cdot 1$ & $0.66[0.61-0.70]$ & Gamez-Diaz2011 & $\cdot 1$ & $0.65[0.58-0.71]$ \\
\hline Dimoula2014 & 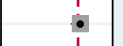 & $0.89[0.82-0.95]$ & Dimoula2014 & 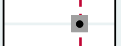 & $0.87[0.83-0.90]$ \\
\hline Davis2006 & $-\frac{1}{4}$ & $0.87[0.72-0.96]$ & Davis2006 & $-\bullet$ & $0.71[0.58-0.82]$ \\
\hline Cardelli2008 & !- & $0.96[0.87-1.00]$ & Cardelli2008 & -6 & $0.92[0.82-0.97]$ \\
\hline Bauer2016 & $\cdot 1$ & $0.76[0.67-0.84]$ & Bauer2016 & -1 & $0.77[0.66-0.85]$ \\
\hline COMBINED & $\phi$ & $0.88[0.81-0.92]$ & COMBINED & $\phi$ & $0.88[0.83-0.91]$ \\
\hline & 1 & $Q=317.92, d f=19.00, p=0.00$ & & 1 & $Q=183.95, d f=19.00, p=0.00$ \\
\hline & 1 & $12=94.02[92.30-95.75]$ & & I & $12=89.67[86.16-93.18]$ \\
\hline \multicolumn{4}{|c|}{$\begin{array}{cc} & 1 \\
0.4 & 1.0 \\
\text { SENSITIVITY }\end{array}$} & \multicolumn{2}{|l|}{$\begin{array}{lr}0.4 & 1.0 \\
\text { SPECIFICITY }\end{array}$} \\
\hline
\end{tabular}


studies reported the diagnostic value of PCT with the following results: pooled sensitivity, 0.82 (95\% CI, 0.78-0.85); pooled specificity, 0.78 (95\% CI, 0.74-0.82) (Fig. 5); pooled PLR, 3.7(95\% CI, 3.1-4.50); pooled NLR, 0.23 (95\% CI, 0.19-0.29); pooled DOR, 16 (95\% CI, 11-23); and the AUC was 0.87 (95\% CI, 0.83-0.89) (Fig. 3b). We found 15 articles reporting the diagnostic value of IL- 6 for sepsis. The results for this set of articles were: pooled sensitivity, 0.72 (95\% CI, 0.65-0.78); pooled specificity, 0.70 (95\% CI, 0.62-0.76) (Fig. 6); pooled PLR, 2.4 (95\% CI, 1.9-3.0); pooled NLR, 0.40 (95\% CI, 0.32-0.51); pooled DOR, 6 (95\% CI, 4.0-9.0); and the AUC was 0.77 (95\% CI, 0.730.80) (Fig. 3c).

\section{Publication bias analysis}

Publication bias of studies regarding neutrophil CD64 showed that 20 articles were not evenly distributed on both sides of the regression line $(t=2.45, P=0.025)$ (Fig. 7a), suggesting a publication bias among the included studies. No significant bias was found for studies addressing PCT $(\mathrm{t}=1.17, P=0.249)$ (Fig. $7 \mathrm{~b})$ or $\mathrm{IL}-6(\mathrm{t}=$ $0.53, P=0.607$ ) (Fig. 7c).

\section{Heterogeneity analysis Meta-regression}

Due to the heterogeneity caused by a non-threshold effect in the included studies, meta-regression was performed when the following criteria were met: a sample size of the study over 100; the patients were Chinese; the average age of patients was over 65 years old; the clinical setting was classified into ICU; and similar test methods were used. The meta-regression of neutrophil CD64 showed that the sample size had an influence on the heterogeneity of sensitivity and specificity, and regional difference was one of the factors that caused the heterogeneity of specificity (Fig. 8a). The meta-regression of PCT showed that the above five factors are likely to be the sources of heterogeneity (Fig. 8b). The metaregression result of IL- 6 indicated that the source of heterogeneity might be the sample size (Fig. 8c).

\section{Sensitivity analysis}

Concerning the sensitivity analysis of neutrophil CD64, we found that when the article by the Gámez-Díaz et al. [37] study was removed from the subset of studies, the

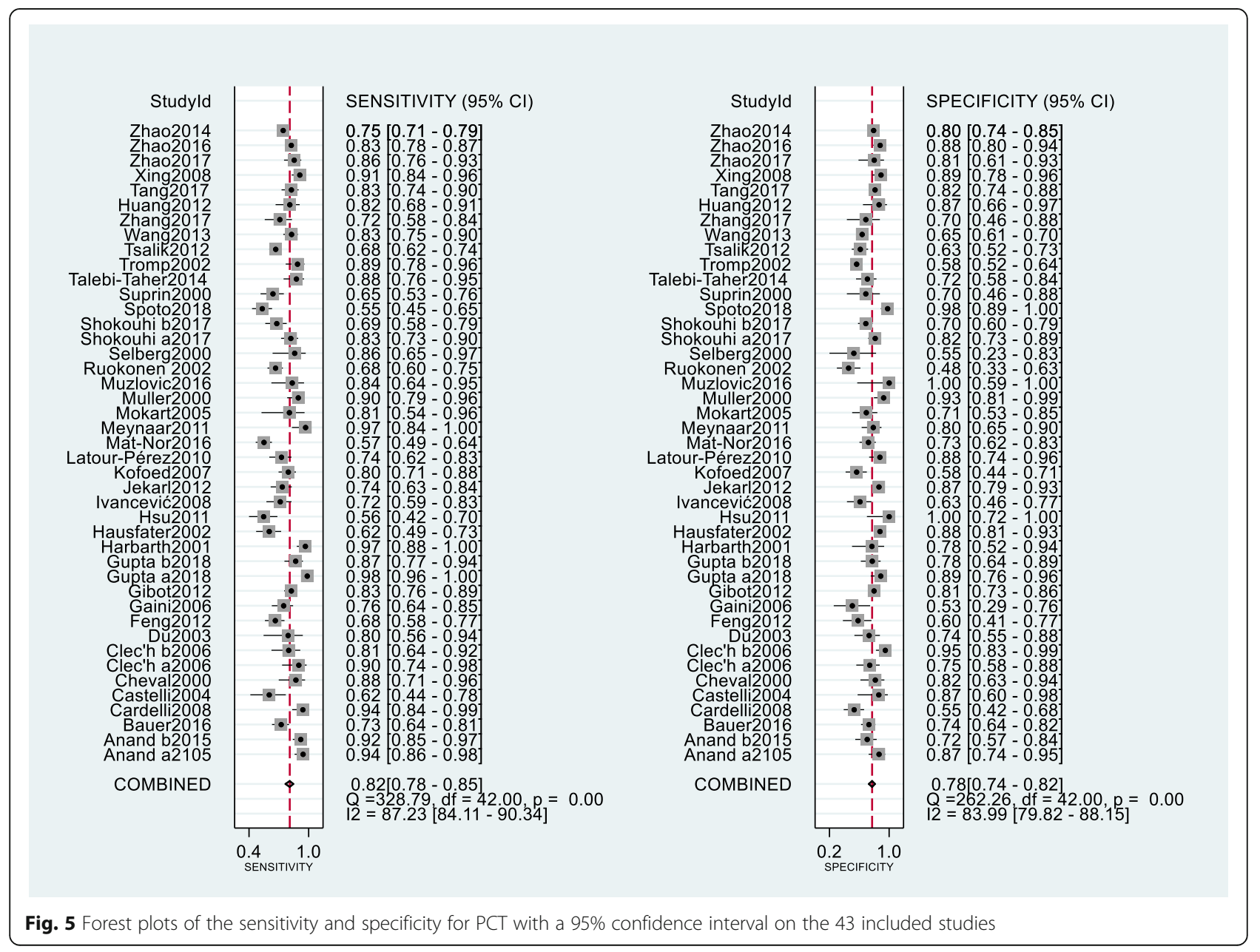




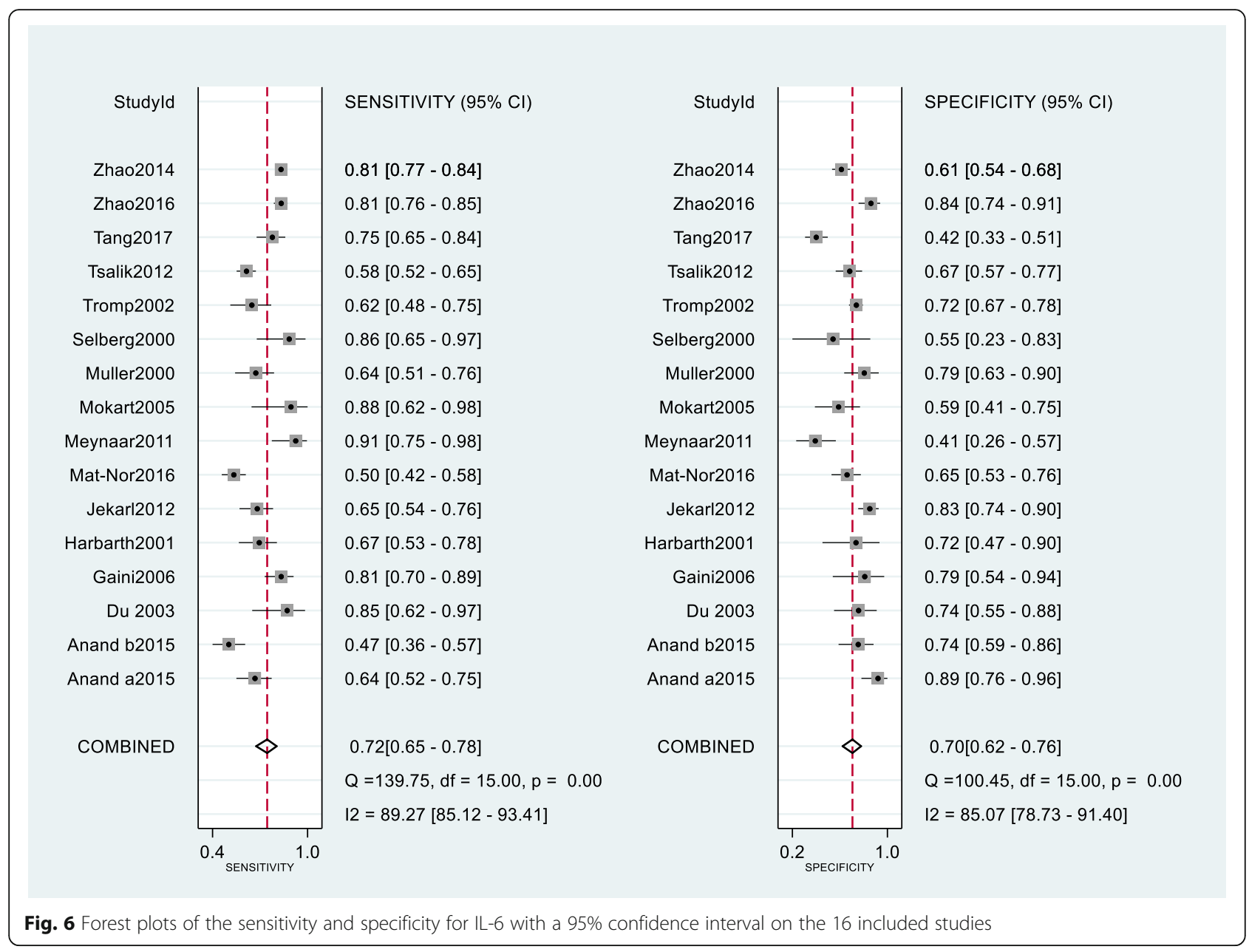

overall heterogeneity of specificity of the 19 articles was decreased, suggesting that the Gámez-Díaz study was the cause for the heterogeneity of specificity (Fig. 9a). When the other 19 studies were removed one by one, the sensitivity, specificity, and AUC showed no significant change. The sensitivity analysis of PCT and IL-6 showed that the sensitivity, specificity, and AUC did not change significantly when they were removed one by one (Fig. 9b, c).

\section{Subgroup analysis}

Through a sensitivity analysis of neutrophil CD64, it was found that the Gámez-Díaz et al. [37] study had an influence on the heterogeneity of neutrophil CD64, so a

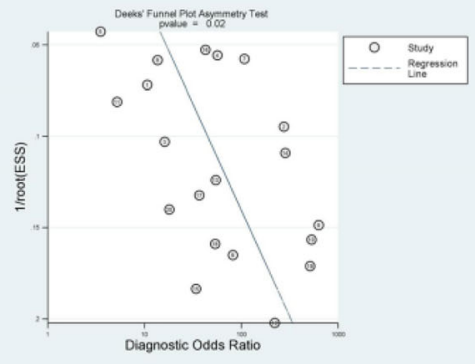

a

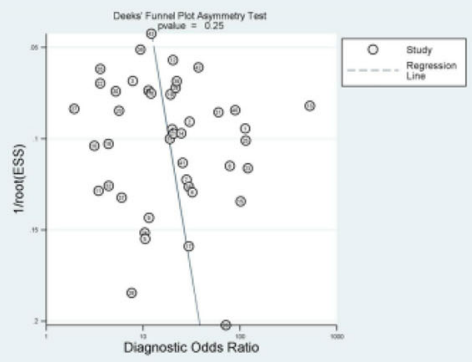

b

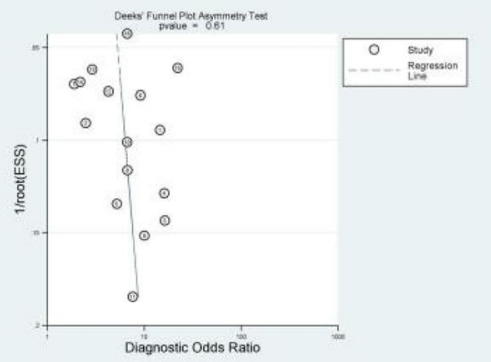

C

Fig. 7 Deeks' funnel figure for the assessment of potential publication bias for neutrophil CD64 (a), PCT (b), and IL-6 (c) expression in the diagnosis of sepsis 


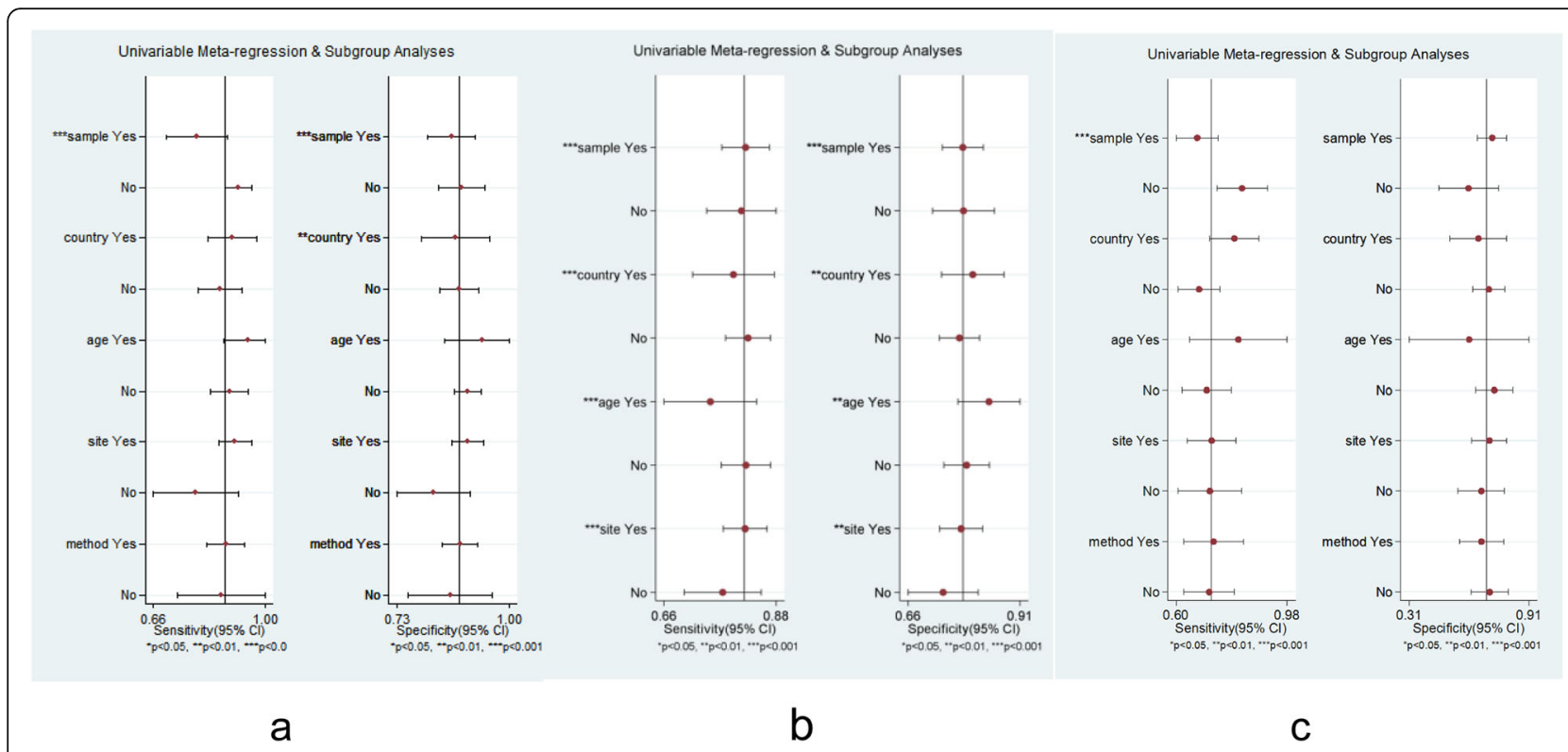

Fig. 8 Meta-regression for neutrophil CD64 (a), PCT (b), and IL-6 (c) expression in the diagnosis of sepsis. Meta-regression was performed according to whether the sample size of the study was over 100, study subjects were Chinese, the average age of the study population was over 65 , and the clinical setting was classified into ICU and measuring methods

subgroup analysis was conducted after excluding such study. The subgroup analysis of three biomarkers indicated that the sample size might be the source of heterogeneity, since the heterogeneity decreased significantly in the group when a small sample size was analyzed, which might be due to the large number of included cases, and a lack of consistency (Tables 2, 3, 4). The subgroup analysis of neutrophil CD64 indicated that regional differences were also a source of heterogeneity, which was consistent with the meta-regression results. Heterogeneity decreased significantly in the Chinese group but remained high in the non-Chinese group. The subgroup analysis showed that the sensitivity, specificity, and AUC of neutrophil CD64 in non-elderly patients were 0.89 (95\% CI, 0.91-0.94), 0.90 (95\% CI, 0.86-0.93),
0.94 (95\% CI, 0.91-0.96), respectively. The sensitivity, specificity, and AUC of PCT in ICU patients were 0.82 (95\% CI, 0.77-0.86), 0.78 (95\% CI, 0.72-0.82), 0.86 (95\% CI, 0.83-0.89), respectively; the SEN, SPE, and AUC of PCT in non-ICU patients were 0.77 (95\% CI, 0.72-0.82), 0.74 (95\% CI, 0.64-0.81), and 0.82 (95\% CI, 0.78-0.85), respectively.

\section{Clinical utility evaluation}

We assumed a pre-test probability of $50 \%$. The Fagan's nomogram of neutrophil CD64 showed a post-test probability of $88 \%$ positive and $12 \%$ negative (Fig. 10a). The Fagan's nomogram of PCT showed a post-test probability of $79 \%$ positive and of $19 \%$ negative (Fig. 10b),

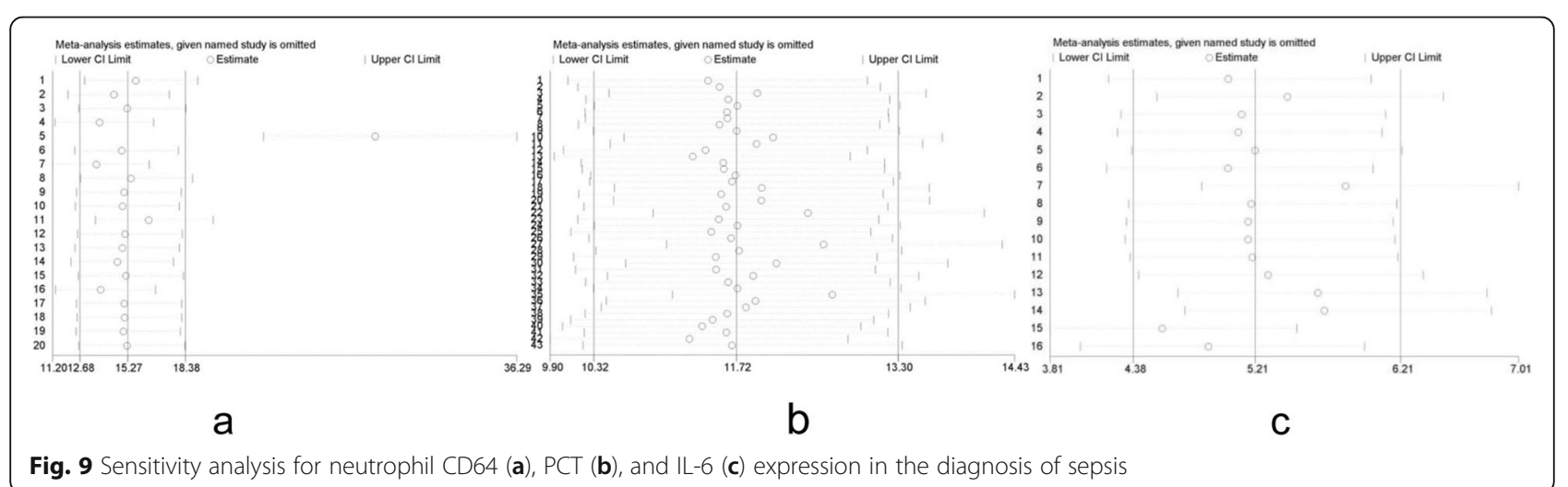


Table 2 Subgroup analysis of CD64 in the diagnosis of sepsis

\begin{tabular}{|c|c|c|c|c|c|c|c|}
\hline category & studies & SEN (95\% Cl) & SPE $(95 \% \mathrm{Cl})$ & DOR $(95 \% \mathrm{Cl})$ & AUC $(95 \% \mathrm{Cl})$ & SEN-I ${ }^{2}(\%)$ & SPE-I $I^{2}(\%)$ \\
\hline overall & 19 & $0.89[0.82,0.93]$ & $0.88[0.84,0.92]$ & $59[30,115]$ & $0.94[0.91,0.96]$ & 90.39 & 76.03 \\
\hline \multicolumn{8}{|c|}{ subgroup analysis based on sample size } \\
\hline size $\geq 100$ & 8 & $0.82[0.71,0.89]$ & $0.87[0.81,0.91]$ & $29[13,64]$ & $0.91[0.88,0.93]$ & 91.53 & 78.72 \\
\hline size $<100$ & 11 & $0.92[0.86,0.96]$ & $0.90[0.84,0.94]$ & $105[44,252]$ & $0.95[0.93,0.97]$ & 62.09 & 13.49 \\
\hline \multicolumn{8}{|c|}{ subgroup analysis based on country } \\
\hline China & 6 & $0.89[0.84,0.93]$ & $0.86[0.80,0.91]$ & $53[30,92]$ & $0.92[0.89,0.94]$ & 49.79 & 0.00 \\
\hline non-China & 13 & $0.88[0.79,0.94]$ & $0.89[0.84,0.93]$ & $64[24,168]$ & $0.94[0.92,0.96]$ & 92.42 & 83.07 \\
\hline \multicolumn{8}{|c|}{ subgroup analysis based on patient scource } \\
\hline ICU & 13 & $0.89[0.80,0.94]$ & $0.90[0.86,0.93]$ & $73[29,183]$ & $0.94[0.92,0.96]$ & 93.18 & 78.96 \\
\hline non-ICU & 4 & - & - & - & - & - & - \\
\hline \multicolumn{8}{|c|}{ subgroup analysis based on assay method } \\
\hline FMC & 16 & $0.87[0.82,0.91]$ & $0.88[0.83,0.91]$ & $50[27,96]$ & $0.94[0.91,0.96]$ & 86.71 & 71.13 \\
\hline Leuko64 kit & 3 & - & - & - & - & - & - \\
\hline \multicolumn{8}{|c|}{ subgroup analysis based on mean age } \\
\hline age $\geq 65$ y & 2 & - & - & - & - & - & - \\
\hline age $<65$ y & 11 & $0.89[0.81,0.94]$ & $0.90[0.86,0.93]$ & $77[37,164]$ & $0.94[0.91,0.96]$ & 90.02 & 61.12 \\
\hline
\end{tabular}

whereas the Fagan's nomogram of IL-6 showed a posttest probability of $70 \%$ positive and of $29 \%$ negative (Fig. 10c).

\section{Discussion}

Our results showed that neutrophil CD64 had the highest diagnostic value for sepsis in adult patients with a pooled sensitivity of 0.88 (95\% CI, 0.81-0.92); pooled specificity of 0.88 (95\% CI, 0.83-0.91); and AUC of 0.94 (95\% CI, 0.91-0.96), followed by PCT, with a pooled sensitivity of 0.82 (95\% CI, $0.78-0.85)$; pooled specificity of 0.78 (95\% CI, 0.74-0.82); and AUC of 0.87 (95\% CI, $0.83-0.89)$. Of all three studied biomarkers, IL-6 showed the weakest diagnostic value for sepsis, with a pooled sensitivity of 0.72 ( $95 \% \mathrm{CI}, 0.65-0.78)$, the pooled specificity of 0.70 (95\% CI, 0.62-0.76), and AUC of 0.77 (95\% CI, 0.73-0.80).

In 2006, Davis et al. [30] reported for the first time the diagnostic potential of neutrophil CD64 in sepsis patients through a retrospective review of 100 blood samples and showed that the performance of neutrophil CD64 was better than white blood cell count, erythrocyte sedimentation, and C-reactive protein as a sepsis diagnostic marker. In the past 10 years, some prospective studies have shown the clinical value of CD64 in the diagnosis of sepsis. In previous studies, Hsu et al. [41]

Table 3 Subgroup analysis of PCT in the diagnosis of sepsis

\begin{tabular}{|c|c|c|c|c|c|c|c|}
\hline category & studies & SEN $(95 \% \mathrm{Cl})$ & SPE $(95 \% \mathrm{Cl})$ & DOR $(95 \% \mathrm{Cl})$ & AUC $(95 \% \mathrm{Cl})$ & SEN-I ${ }^{2}(\%)$ & SPE-I $I^{2}(\%)$ \\
\hline overall & 43 & $0.82[0.78,0.85]$ & $0.78[0.74,0.82]$ & $16[11,23]$ & $0.87[0.83,0.89]$ & 87.23 & 83.99 \\
\hline \multicolumn{8}{|c|}{ subgroup analysis based on sample size } \\
\hline size $\geq 100$ & 27 & $0.82[0.77,0.86]$ & $0.78[0.73,0.83]$ & $16[11,25]$ & $0.87[0.84,0.90]$ & 90.42 & 88.98 \\
\hline size $<100$ & 16 & $0.81[0.74,0.86]$ & $0.78[0.71,0.83]$ & $15[9.25]$ & $0.86[0.83,0.89]$ & 74.74 & 52.18 \\
\hline \multicolumn{8}{|c|}{ subgroup analysis based on country } \\
\hline China & 11 & $0.79[0.74,0.84]$ & $0.79[0.73,0.85]$ & $15[8,26]$ & $0.86[0.83,0.89]$ & 78.26 & 83.92 \\
\hline non-China & 33 & $0.83[0.77,0.87]$ & $0.77[0.72,0.82]$ & $16[11,25]$ & $0.87[0.84,0.89]$ & 89.29 & 84.48 \\
\hline \multicolumn{8}{|c|}{ subgroup analysis based on patient scource } \\
\hline ICU & 27 & $0.82[0.77,0.86]$ & $0.78[0.72,0.82]$ & $16[10,24]$ & $0.86[0.83,0.89]$ & 86.20 & 76.10 \\
\hline non-ICU & 10 & $0.77[0.72,0.82]$ & $0.74[0.64,0.81]$ & $9[6,15]$ & $0.82[0.78,0.85]$ & 74.39 & 90.16 \\
\hline \multicolumn{8}{|c|}{ subgroup analysis based on mean age } \\
\hline age $\geq 65$ y & 8 & $0.79[0.72,0.8]$ & $0.84[0.75,0.90]$ & $20[12,34]$ & $0.88[0.85,0.91]$ & 86.45 & 74.39 \\
\hline age $<65$ y & 20 & $0.80[0.73,0.86]$ & $0.81[0.76,0.85]$ & $17[10,29]$ & $0.87[0.84,0.90]$ & 84.01 & 73.73 \\
\hline
\end{tabular}


Table 4 Subgroup analysis of IL-6 in the diagnosis of sepsis

\begin{tabular}{|c|c|c|c|c|c|c|c|}
\hline category & studies & SEN $(95 \% \mathrm{Cl})$ & SPE $(95 \% \mathrm{Cl})$ & DOR $(95 \% \mathrm{Cl})$ & AUC $(95 \% \mathrm{Cl})$ & SEN-1 ${ }^{2}(\%)$ & SPE-I $I^{2}(\%)$ \\
\hline overall & 16 & $0.72[0.65,0.78]$ & $0.70[0.62,0.76]$ & $6[4,9]$ & $0.77[0.73,0.80]$ & 89.27 & 85.07 \\
\hline \multicolumn{8}{|c|}{ subgroup analysis based on sample size } \\
\hline size $\geq 100$ & 10 & $0.66[0.58,0.3]$ & $0.73[0.64,0.80]$ & $5[3,8]$ & $0.75[0.71,0.78]$ & 92.34 & 88.99 \\
\hline size $<100$ & 6 & $0.83[0.73,0.83]$ & $0.64[0.51,0.75]$ & $8[5,14]$ & $0.81[0.77,0.84]$ & 52.42 & 62.91 \\
\hline \multicolumn{8}{|c|}{ subgroup analysis based on country } \\
\hline China & 4 & - & - & - & - & - & - \\
\hline non-China & 12 & $0.69[0.59,0.77]$ & $0.70[0.63,0.77]$ & $5[3,8]$ & $0.75[0.71,0.79]$ & 80.86 & 74.47 \\
\hline \multicolumn{8}{|c|}{ subgroup analysis based on patient scource } \\
\hline ICU & 10 & $0.71[0.60,0.80]$ & $0.74[0.66,0.81]$ & $8[4,14]$ & $0.80[0.76,0.83]$ & 91.94 & 80.76 \\
\hline non-ICU & 6 & $0.73[0.64,0.80]$ & $0.66[0.54,0.75]$ & $5[3,8]$ & $0.74[0.70,0.78]$ & 84.28 & 84.97 \\
\hline \multicolumn{8}{|c|}{ subgroup analysis based on assay method } \\
\hline EIA & 8 & $0.75[0.64,0.83]$ & $0.70[0.63,0.76]$ & $7[4,12]$ & $0.77[0.73,0.81]$ & 91.31 & 67.89 \\
\hline ECLI & 8 & $0.69[0.59,0.77]$ & $0.69[0.56,0.80]$ & $5[3,9]$ & $0.75[0.71,0.78]$ & 83.28 & 90.73 \\
\hline \multicolumn{8}{|c|}{ subgroup analysis based on mean age } \\
\hline age $\geq 65$ y & 1 & - & - & - & - & - & - \\
\hline age $<65$ y & 9 & $0.71[0.61,0.79]$ & $0.74[0.63,0.82]$ & $7[4,13]$ & $0.78[0.75,0.82]$ & 90.46 & 90.59 \\
\hline
\end{tabular}

found that the accuracy of neutrophil CD64 was better than PCT in respiratory intensive care unit patients to distinguish systemic inflammatory response syndrome from severe sepsis and septic shock. Neutrophil CD64 was also found to be associated with mortality. However, some studies criticized the diagnostic value of neutrophil CD64 in sepsis. Gros et al. [38] showed that neutrophil CD64 has a low sensitivity in the diagnosis of sepsis in
ICU or emergency department patients. However, due to its high specificity, when combined with other sensitive markers, it may contribute to the clinical diagnosis of sepsis. In 2016, Wang et al. [70] conducted a metaanalysis with 8 studies written in English, to assess the value of neutrophil CD64 for the diagnosis of sepsis. The results showed that the pooled sensitivity, specificity, and AUC were 0.76, 0.85, and 0.95 respectively,

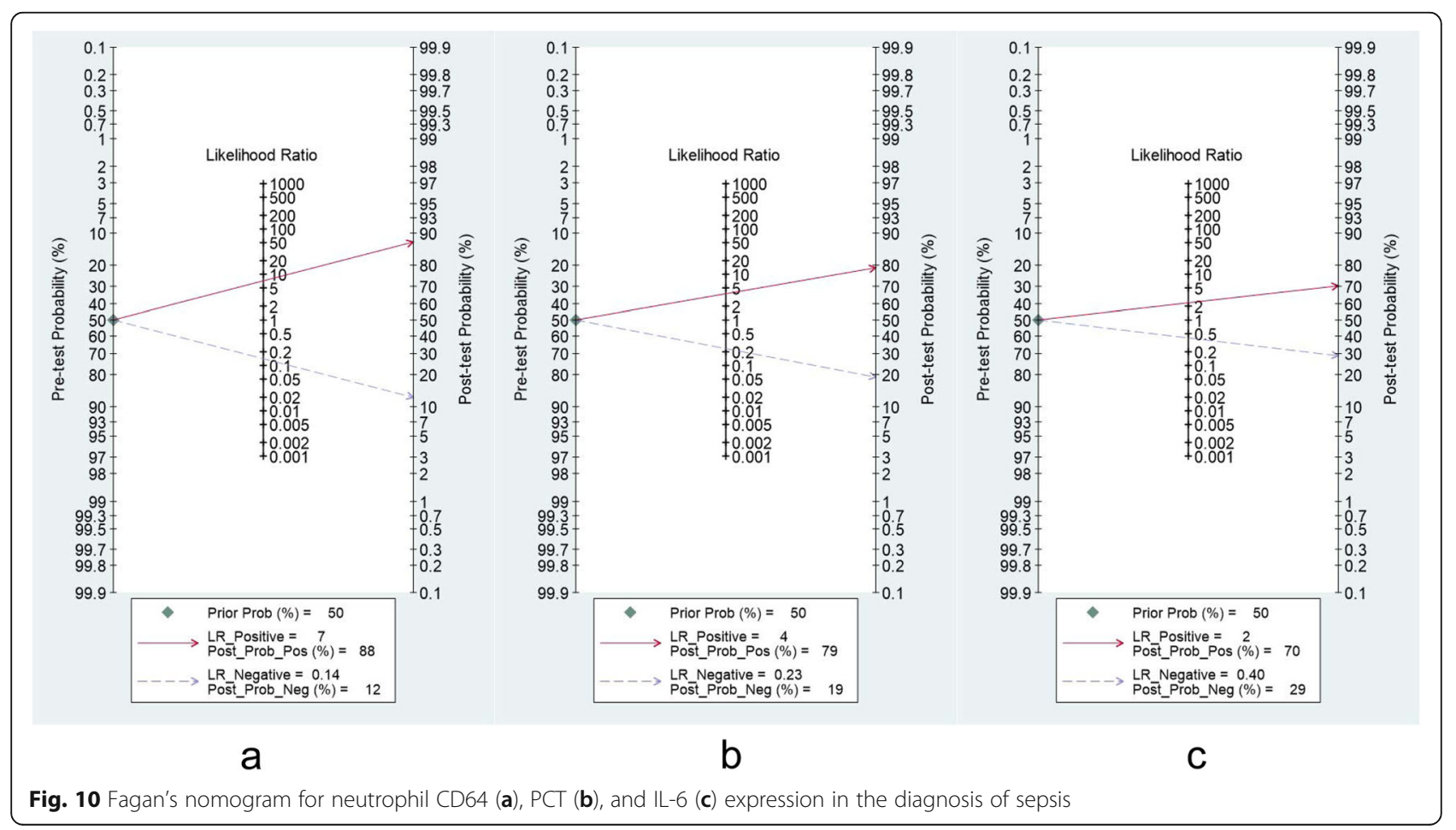


which suggested that neutrophil CD64 had a high specificity for sepsis. However, because of its low sensitivity, it could not be used alone in the diagnosis of sepsis. Our meta-analysis searched publications in more databases than other published meta-analysis, more comprehensive clinical research data was collected, and the results were more persuasive. In our study, 20 studies were included, showing that the neutrophil CD64 test has a high sensitivity and specificity in adult sepsis patients, and was superior to the traditional biomarkers PCT and IL-6. Li et al. [71] carried out a meta-analysis to evaluate the diagnostic value of CD64 in infectious diseases, including adults and newborns. The results showed that the pooled sensitivity, specificity, and AUC were $0.76,0.85$, and 0.92 respectively, which suggested that the neutrophil CD64 had a high specificity in sepsis. Due to the uniqueness of neonate sepsis in many aspects, our study only included studies on adult sepsis patients.

Although IL-6 is weaker than the neutrophil CD64 and PCT in the diagnosis of sepsis in adult patients, some studies have shown that it also plays a role in the prognosis of infectious diseases [72, 73]. Studies have found that the level of IL- 6 in the blood of patients with Gram-negative bacterial infection is significantly higher than those with Gram-positive bacterial infection [74], indicating that IL-6 has a certain suggestive effect on the pathogenic bacteria. Zhao et al. [75] through the regression analysis results show that a combination of the three biomarkers (PCT, IL-6, and D-dimer) can effectively improve the diagnosis of sepsis and severe sepsis. However, joint diagnosis in clinical research data is uncommon and there is not enough to apply to metaanalysis for data integration to further explore this topic.

We used sensitivity analysis, meta-regression, and subgroup analysis to explore the heterogeneity of data. The sensitivity analysis showed that the heterogeneity decreased significantly when the Gámez-Díaz et al. [35] study was omitted. The sample size of this study was the largest among all included studies, and the study results were negative, which could lead to an increase in heterogeneity. The meta-regression and subgroup analysis indicated several factors can explain the heterogeneity that we observed, including regional difference, differently aged patients, the sample size, the severity of the disease, and test methods. Through the subgroup analysis of the articles, we found that the specificity of the neutrophil CD64 in non-elderly patients has increased compared to all ages. Further studies to determine the accuracy of neutrophil CD64 in differently aged patients are required. PCT in the ICU group has a higher diagnostic efficacy for sepsis than in the non-ICU group. The study of Yunus et al. [76] found PCT was positively correlated with the severity of sepsis. Because the proportion of patients with severe sepsis and septic shock among ICU patients was large, the PCT in the ICU patients showed a better diagnostic efficiency. PCT had a better diagnostic value in critically ill patients than in those with nonsevere conditions.

Our research is limited by some factors. Firstly, the heterogeneity in the study is high. Although some sources of heterogeneity have been found through metaregression, sensitivity analysis, and subgroup analysis, there are still other unidentified sources. Secondly, there is a publication bias in the analysis of the diagnostic accuracy of sepsis toward neutrophil CD64. In the follow-up of this study, the scope should be expanded to overcome the publication bias. Thirdly, only Chinese and English language literature was included, which might exclude relevant data. Fourthly, due to the different test methods for the three biomarkers, the cut-off values varied between the included studies. Future studies are needed to determine the optimal cut-off value of biomarkers that confers the diagnostic value for sepsis.

\section{Conclusions}

Among the three biomarkers, neutrophil CD64 has the highest diagnostic value for sepsis in adult patients, followed by PCT and IL-6. In the diagnosis of sepsis, the diagnostic value of PCT in severe patients is better than that in non-severe patients.

\section{Abbreviations \\ AUC: Area under the curve; DOR: Diagnostic odds ratio; FN: False negative; FP: False positive; ICU: Intensive care unit; IL-6: Interleukin-6; LPS: Lipopolysaccharides; NLR: Negative likelihood ratio; PCT: Procalcitonin; PLR: Positive likelihood ratio; QUADAS: Quality Assessment for Diagnostic Accuracy Studies; SEN: Sensitivity; SOFA: Sequential Organ Failure Assessment; SPE: Specificity; SROC: Summary Receiver Operating Characteristic; TN: True negative; TP: True positive}

Acknowledgements

We thank the patients taking part in the original studies.

\section{Authors' contributions}

SC and KW are the primary authors who are responsible for the entire project. TGM and CT contributed to the systematic literature review and database search. XD and MZ performed the data collection and reference search. SC and TGM analyzed the data and drafted the writing of the manuscript. KW drafted the first revision of the manuscript. All authors approved the interpretation of the results and took part in the final revision of the manuscript. Conceptualization: SC and TGM. Data curation: XD. Formal analysis: SC. Funding acquisition: XD and KW. Investigation:CT and MZ. Methodology: SC and TGM. Project administration: KW. Resources: CT and MZ. Software:SC and CT. Supervision: KW. Writing - original draft: SC. Writing - review and editing: KW. The authors read and approved the final manuscript.

\section{Funding}

This work was supported by the Special Funding for Clinical Research of Wu Jieping Medical Foundation [grant numbers 320.6750.18357] and the Science and Technology Development Plan Project of Jilin Province [grant numbers 20190303162SF] to Ke Wang.

Availability of data and materials

All relevant data supporting the conclusion of this study are included within the paper. 


\section{Declarations}

Ethics approval and consent to participate

Ethics approval was not applicable for this meta-analysis.

\section{Consent for publication}

Not applicable.

\section{Competing interests}

The authors declare that they have no competing interests.

Received: 16 August 2020 Accepted: 9 April 2021

Published online: 26 April 2021

\section{References}

1. Rudd KE, Johnson SC, Agesa KM, Shackelford KA, Tsoi D, Kievlan DR, et al. Global, regional, and national sepsis incidence and mortality, 1990-2017: analysis for the Global Burden of Disease Study. Lancet. 2020;395(10219): 200-11. https://doi.org/10.1016/S0140-6736(19)32989-7.

2. Verdonk F, Blet A, Mebazaa A. The new sepsis definition: limitations and contribution to research and diagnosis of sepsis. Curr Opin Anaesthesiol. 2017;30(2):200-4. https://doi.org/10.1097/aco.0000000000000446.

3. Levy MM, Fink MP, Marshall JC, Abraham E, Angus D, Cook D, et al. 2001 SCCM/ESICM/ACCP/ATS/SIS international Sepsis definitions conference. Crit Care Med. 2003;31(4):1250-6. https://doi.org/10.1097/01.Ccm.0000050454.01 978.3b.

4. Marik PE, Taeb AM. SIRS, qSOFA and new sepsis definition. J Thorac Dis. 2017;9(4):943-5. https://doi.org/10.21037/jtd.2017.03.125.

5. Williams JM, Greenslade JH, McKenzie JV, Chu K, Brown AFT, Lipman J. Systemic inflammatory response syndrome, quick sequential organ function assessment, and organ dysfunction insights from a prospective database of ed patients with infection. Chest. 2017;151(3):586-96. https://doi.org/10.101 6/j.chest.2016.10.057

6. Cheng MP, Stenstrom R, Paquette K, Stabler SN, Akhter M, Davidson AC, et al. Blood culture results before and after antimicrobial administration in patients with severe manifestations of sepsis: a diagnostic study. Ann Intern Med. 2019;171(8):547. https://doi.org/10.7326/m19-1696.

7. Gguolong C, Jing Y, Haibo Q. Guidelines for the treatment of severe sepsis/ septic shock in China (2014):norms and practices. Chin J Internal Med. 2015; 54(6):484-5 (In Chinese).

8. Wagner C, Deppisch R, Denefleh B, Hug F, Andrassy K, Hänsch GM. Expression patterns of the lipopolysaccharide receptor CD14, and the FCgamma receptors CD16 and CD64 on polymorphonuclear neutrophils: data from patients with severe bacterial infections and lipopolysaccharideexposed cells. Shock. 2003;19(1):5-12. https://doi.org/10.1097/00024382-2 00301000-00002

9. Hoffmann JJML. Neutrophil CD64 as a sepsis biomarker. Biochem Med. 2011;21(3):282-90

10. Davies J. Procalcitonin. J Clin Pathol. 2015;68(9):675-9. https://doi.org/10.113 6/jclinpath-2014-202807.

11. Matwiyoff GN, Prahl JD, Miller RJ, Carmichael JJ, Amundson DE, Seda G, et al. Immune regulation of procalcitonin: a biomarker and mediator of infection. Inflamm Res. 2012;61 (5):401-9. https://doi.org/10.1007/s00011-0120439-5.

12. Vijayan AL, Ravindran S, Saikant R, Lakshmi S, Kartik R, Manoj G. Procalcitonin:a promising diagnostic marker for sepsis and antibiotic therapy. J Intensive Care. 2017;5(1):51. https://doi.org/10.1186/s40560-0170246-8.

13. Yuzbasioglu Y, Duymaz H, Tanrikulu CS, Halhalli HC, Koc MO, Tandoğan M, et al. Role of Procalcitonin in evaluation of the severity of acute Cholecystitis. Eur J Med. 2016;48(3):162-6. https://doi.org/10.5152/eurasia nmedj.2016.0052.

14. Iwase S, Nakada T, Hattori N, Takahashi W, Takahashi N, Aizimu T, et al. Interleukin-6 as a diagnostic marker for infection in critically ill patients: a systematic review and meta-analysis. Am J Emerg Med. 2019;37(2):260-5. https://doi.org/10.1016/j.ajem.2018.05.040.

15. Wakabayashi A, Sawada K, Nakayama M, Toda A, Kimoto A, Mabuchi S, et al. Targeting interleukin-6 receptor inhibits preterm delivery induced by inflammation. Mol Hum Reprod. 2013;19(11):718-26. https://doi.org/10.1093/ molehr/gat057.
16. Ivancević N, Radenković D, Bumbasirević V, Karamarković A, Jeremić V, Kalezić $\mathrm{N}$, et al. Procalcitonin in preoperative diagnosis of abdominal sepsis. Langenbecks Arch Surg. 2008;393(3):397-403. https://doi.org/10.1007/ s00423-007-0239-5.

17. Muzlovic I, Ihan A, Stubljar D. CD64 index on neutrophils can diagnose sepsis and predict 30-day survival in subjects after ventilator-associated pneumonia. J Infect Dev Ctries. 2016;10(3):260-8. https://doi.org/10.3855/ jidc.6532.

18. Mokart D, Merlin M, Sannini A, Brun JP, Delpero JR, Houvenaeghel G, et al. Procalcitonin, interleukin 6 and systemic inflammatory response syndrome (SIRS): early markers of postoperative sepsis after major surgery. $\mathrm{Br} \mathrm{J}$ Anaesth. 2005;94(6):767-73. https://doi.org/10.1093/bja/aei143.

19. Lu H, Zhou J, Wang YL, Chen X. Early diagnosis value of CD64 index levels in peripheral blood on postoperative traumatic sepsis. J Region Anatomy Operative Surg. 2016;25(05):339-42 (In Chinese).

20. Talebi-Taher M, Babazadeh S, Barati M, Latifnia M. Serum inflammatory markers in the elderly: are they useful in differentiating sepsis from SIRS? Acta Med Iran. 2014;52(6):438-42.

21. Zhang HM, Wang XT, Zhang Q, Xia Y, Liu DW. Comparison of procalcitonin and high-sensitivity C-reactive protein for the diagnosis of sepsis and septic shock in the oldest old patients. BMC Geriatr. 2017;17(1):173. https://doi. org/10.1186/s12877-017-0566-5.

22. Shokouhi B, Bookani KR, Ghasemi H, Khalouei M, Rezaei NJ, Samani SM. Diagnostic and prognostic performances of serum procalcitonin in patients with blood stream infections: a parallel, case-control study comprising adults and elderly. Rev Assoc Med Bras. 2017;63(6):521-6. https://doi.org/1 0.1590/1806-9282.63.06.521.

23. Anand D, Das S, Bhargava S, Srivastava LM, Garg A, Tyagi N, et al. Procalcitonin as a rapid diagnostic biomarker to differentiate between culture-negative bacterial sepsis and systemic inflammatory response syndrome:a prospective, observational, cohort study. J Crit Care. 2015;30(1): 218.e7. https://doi.org/10.1016/j.jcrc.2014.08.017.

24. Gupta S, Jaswani P, Sharma RK, Agrawal S, Prasad N, Sahu C, et al. Procalcitonin as a diagnostic biomarker of sepsis: a tertiary care Centre experience. J Infect Public Health. 2019;12(3):323-9. https://doi.org/10.1016/j. jiph.2018.11.004.

25. Clec'h C, Fosse JP, Karoubi P, Vincent F, Chouahi I, Hamza L, et al. Differential diagnostic value of procalcitonin in surgical and medical patients with septic shock. Crit Care Med. 2006;34(1):102-7. https://doi.org/1 0.1097/01.Ccm.0000195012.54682.F3.

26. Bauer PR, Kashyap R, League SC, Park JG, Block DR, Baumann NA, et al. Diagnostic accuracy and clinical relevance of an inflammatory biomarker panel for sepsis in adult critically ill patients. Diagn Microbiol Infect Dis. 2016;84(2):175-80. https://doi.org/10.1016/j.diagmicrobio.2015.10.003.

27. Cardelli P, Ferraironi M, Amodeo R, Tabacco F, De Blasi RA, Nicoletti M, et al. Evaluation of neutrophil CD64 expression and procalcitonin as useful markers in early diagnosis of sepsis. Int I Immunopathol Pharmacol. 2008; 21(1):43-9. https://doi.org/10.1177/039463200802100106.

28. Castelli GP, Pognani C, Meisner M, Stuani A, Bellomi D, Sgarbi L. Procalcitonin and C-reactive protein during systemic inflammatory response syndrome, sepsis and organ dysfunction. Crit Care. 2004;8(4):R234-42. https://doi.org/10.1186/cc2877.

29. Cheval C, Timsit JF, Garrouste-Orgeas M, Assicot M, De Jonghe B, Misset B, et al. Procalcitonin $(P C T)$ is useful in predicting the bacterial origin of an acute circulatory failure in critically ill patient. Intensive Care Med. 2000; 26(Suppl 2):S153-8. https://doi.org/10.1007/bf02900729.

30. Davis BH, Olsen SH, Ahmad E, Bigelow NC. Neutrophil CD64 is an improved indicator of infection or sepsis in emergency department patients. Arch Pathol Lab Med. 2006;130(5):654-61. https://doi.org/10.5858/2006-130-654-NCIAll.

31. Dimoula A, Pradier O, Kassengera Z, Dalcomune D, Turkan H, Vincent JL. Serial determinations of neutrophil CD64 expression for the diagnosis and monitoring of sepsis in critically ill patients. Clin Infect Dis. 2004;58(6):820-9. https://doi.org/10.1093/cid/cit936.

32. Du B, Pan JQ, Chen DC, Li Y. Serum procalcition and interleukin-6 levels may help to differentiate systemic inflammatory response of infectious orgin. Chin Med J. 2003;116(4):538-42.

33. Feng $L$, Zhou X, Su LX, Feng D, Jia YH, Xie LX. Clinical significance of soluble hemoglobin scavenger receptor CD163 (sCD163) in sepsis, a prospective study. PLoS One. 2012;7(7):e38400. https://doi.org/10.1371/journal.pone.0038400.

34. Gaïn S, Koldkjaer OG, Moller HJ, Pedersen C, Pedersen SS. A comparison of high-mobility group-box 1 protein, lipopolysaccharide-binding protein and 
procalcitonin in severe community-acquired infections and bacteraemia: a prospective study. Crit Care. 2007;11(4):R76. https://doi.org/10.1186/cc5967.

35. Gámez-Díaz LY, Enriquez LE, Matute JD, Velásquez S, Gómez ID, Toro F, et al. Diagnostic accuracy ofHMGB-1,STREM-1, and CD64 as markers of sepsis in patients recently admitted to the emergency department. Acad Emerg Med. 2011;18(8):807-15. https://doi.org/10.1111/j.1553-2712.2011.01113.x.

36. Gerrits JH, McLaughlin PMJ, Nienhuis BN, Smit JW, Loef B. Polymorphic mononuclear neutrophils CD64 index for diagnosis of sepsis in postoperative surgical patients and critically ill patients. Clin Chem Lab Med. 2013;51(4):897-905. https://doi.org/10.1515/cclm-2012-0279.

37. Gibot S, Béné MC, Noel R, Massin F, Guy J, Cravoisy A, et al. Combination biomarkers to diagnose sepsis in the critically ill patient. Am J Respir Crit Care Med. 2012;186(1):65-71. https://doi.org/10.1164/rccm.201201-00370C.

38. Gros A, Roussel M, Sauvadet E, Gacouin A, Marqué S, Chimot L, et al. The sensitivity of neutrophil CD64 expression as a biomarker of bacterial infection is low in critically ill patients. Intensive Care Med. 2012;38(3):44552. https://doi.org/10.1007/s00134-012-2483-6.

39. Harbarth S, Holeckova K, Froidevaux C, Pittet D, Ricou B, Grau GE, et al. Diagnostic value of procalcitonin, interleukin-6, and interleukin-8 in critically ill patients admitted with suspected sepsis. Am J Respir Crit Care Med. 2001; 164(3):396-402. https://doi.org/10.1164/ajrccm.164.3.2009052.

40. Hausfater P, Garric S, Ayed SB, Rosenheim M, Bernard M, Riou B. Usefulness of procalcitonin as a marker of systemic infection in emergency department patients: a prospective study. Clin Infect Dis. 2002;34(7):895-901. https://doi. org/10.1086/339198.

41. Hsu KH, Chan MC, Wang JM, Lin LY, Wu CL. Comparison of fC gamma receptor expression on neutrophils with procalcitonin for the diagnosis of sepsis in critically ill patients. Respirology. 2011;16(1):152-60. https://doi. org/10.1111/j.1440-1843.2010.01876.x.

42. Jämsä J, Huotari V, Savolainen ER, Syrjälä H, Ala-Kokko T. Kinetics of leukocyte CD11b and CD64 expression in severe sepsis and non-infectious critical care patients. Acta Anaesthesiol Scand. 2015;59(7):881-91. https://doi. org/10.1111/aas.12515.

43. Jekarl DW, Lee SY, Lee J, Park YJ, Kim Y, Park JH, et al. Procalcitonin as a diagnostic marker and IL-6 as a prognostic marker for sepsis. Diagn Microbiol Infect Dis. 2013;75(4):342-7. https://doi.org/10.1016/j.dia gmicrobio.2012.12.011.

44. Kofoed K, Andersen O, Kronborg G, Tvede M, Petersen J, Eugen-Olsen J, et al. Use of plasma C-reactive protein,procalcitonin, neutrophils, macrophage migration inhibitory factor, soluble urokinase-type plasminogen activator receptor, and soluble triggering receptor expressed on myeloid cells-1 in combination to diagnose infections: a prospective study. Crit Care. 2007;11(2):R38. https://doi.org/10.1186/cc5723.

45. Latour-Pérez J, Alcalá-López A, García-García MA, Sánchez-Hernández JF, Abad-Terrado C, Viedma-Contreras JA, et al. Diagnostic accuracy of sTREM-1 to identify infection in critically ill patients with systemic inflammatory response syndrome. Med Int. 2010;43(9):720-4. https://doi.org/10.1016/j. clinbiochem.2010.03.001.

46. Lewis SM, Treacher DF, Edgeworth J, Mahalingam G, Brown CS, Mare TA, et al. Expression of CD11C and EMR2 on neutrophils:potential diagnostic biomarkers for sepsis and systemic inflammation. Clin Exp Immunol. 2015; 182(2):184-94. https://doi.org/10.1111/cei.12679.

47. Mat-Nor MB, Ralib AMD, Abdulah NZ, Pickering JW. The diagnostic ability of procalcitonin and interleukin-6 to differentiate infectious from noninfectious systemic inflammatory response syndrome and to predict mortality. J Crit Care. 2016;33:245-51. https://doi.org/10.1016/j.jcrc.2016.01.002.

48. Meynaar IA, Droog W, Batstra M, Vreede R, Herbrink P. In critically ill patients, serum procalcitonin is more useful in differentiating between sepsis and SIRS than CRP, IL-6, or LBP. Crit Care Res Pract. 2011;2011: 594645-6. https://doi.org/10.1155/2011/594645.

49. Müller B, Becker KL, Schächinger H, Rickenbacher PR, Huber PR, Zimmerli W, et al. Calcitonin precursors are reliable markers of sepsis in a medical intensive care unit. Crit Care Med. 2000;28(4):977-83. https://doi.org/10.1 097/00003246-200004000-00011.

50. Papadimitriou-Olivgeris M, Lekka K, Zisimopoulos K, Spiliopoulou I, Logothetis D, Theodorou G, et al. Role of CD64 expression on neutrophils in the diagnosis of sepsis and the prediction of mortality in adult critically ill patients. Diagn Microbiol Infect Dis. 2015;82(3):234-9. https://doi.org/10.101 6/j.diagmicrobio.2015.03.022.

51. Righi S, Santambrogio L, Monsagrati A, Saliu M, Locati L, Radrizzani D. Clinical evaluation of neutrophil CD64 as a diagnostic marker of infection in a poly valent intensive care unit. Infect Dis Clin Pract. 2014;22(1):32-7. https://doi.org/10.1097/IPC.0b013e31828f4b6a.

52. Ruokonen $\mathrm{E}$, Ilkka L, Niskanen M, Takala J. Procalcitonin and neopterin as indicators of infection in critically ill patients. Acta Anaesthesiol Scand. 2002; 46(4):398-404. https://doi.org/10.1034/j.1399-6576.2002.460412.x.

53. Selberg $\mathrm{O}$, Hecker $H$, Martin M, Klos A, Bautsch W, Köhl J. Discrimination of sepsis and systemic inflammatory response syndrome by determination of circulating plasma concentrations of procalcitonin, protein complement 3a, and interleukin-6. Crit Care Med. 2000;28(4):2793-8. https://doi.org/10.1097/ 00003246-200008000-00019.

54. Spoto S, Cella E, de Cesaris M, Locorriere L, Mazzaroppi S, Nobile E, et al. Procalcitonin and mr-proadrenomedullin combination with SOFA and qSOFA scores for sepsis diagnosis and prognosis: a diagnostic algorithm. Shock. 2018;50(1):44-52. https://doi.org/10.1097/shk. 0000000000001023.

55. Suprin E, Camus C, Gacouin A, Le Tulzo Y, Lavoue S, Feuillu A, et al. Procalcitonin: a valuable indicator of infection in a medical ICU? Intensive Care Med. 2000;26(9):1232-8. https://doi.org/10.1007/s001340000580.

56. Tan TL, Ahmad NS, Nasuruddin DN, Ithnin A, Arifin K, Zaini IZ, et al. CD64 and group II secretory phospholipase A2(SPLA2-IIA) as biomarkers for distinguishing adult sepsis and bacterial infections in the emergency department. PLoS One. 2016;11(3):e0152065. https://doi.org/10.1371/journal. pone.0152065.

57. Tromp M, Lansdorp B, Bleeker-Rovers CP, Gunnewiek JMK, Kullberg BJ, Pickkers P. Serial and panel analyses of biomarkers do not improve the prediction of bacteremia compared to one procalcitonin measurement. J Inf Secur. 2012;65(4):292-301. https://doi.org/10.1016/j.jinf.2012.06.004.

58. Tsalik EL, Jaggers LB, Glickman SW, Langley RJ, van Velkinburgh JC, Park LP, et al. Discriminative value of inflammatory biomarkers for suspected sepsis. J Emerg Med. 2012;43(1):97-106. https://doi.org/10.1016/j.jemermed.2011.05.072.

59. Wang $H$, Yin F, Shen DX, Zhang YJ, Luo YP, Liu CJ, et al. Predictive value of procalcitonin for excluding bloodstream infection:results of a retrospective study and utility of a rapid, quantitative test for procalcitonin. J Int Med Res. 2013:41(5):1671-81. https://doi.org/10.1177/0300060513497558.

60. Huang WP, Jiang WQ, Hu B, Ye H, Zeng HK. Significance of serum procalcitonin levels in the evaluation of severity and prognosis of patients with systemic inflammatory response syndrome. Chin Crit Care Med. 2012; 05(24):294-7 (In Chinese).

61. Shao JS, Zhou LX, Li YN, Chen S, Yu TO. Diagnostic application of neutrophil CD64 expression in sepsis. Chin J Crit Care Med. 2014;34(7):1-4 (In Chinese).

62. Tang YM, Cai QW, Ye YS, Lei ZH. Three indicators combined detection of the application of ICU in early diagnosis of sepsis patients. Int J Lab Med. 2017;38(01):61-2 (In Chinese).

63. Wang $\mathrm{B}$, Wang $\mathrm{H}$. Clinical value of $\mathrm{C}$-reactive protein, procalcitonin, neutrophil surface CD35 and CD64 in the diagnosis of sepsis. J Clin Exp Med. 2017;16(08):752-5 (In Chinese).

64. Xing YB, Dai LM, Zhao ZH, Li ZW, Li C. Diagnostic and prognostic value of procalcitonin and common inflammatory markers combining SOFA score in patients with sepsis in early stage. Chin Crit Care Med. 2008;20(01):23-8 (In (hinese).

65. Xu JY, Chen JH, Ou YJ, Gu Q, Liu Y, Wang Y. Early diagnosis value of neutrophil CD64 in adult sepsis. Chin J Hosp Infect Dis. 2009;19(05):596-8 (In Chinese).

66. Zhang H, Yi SH, Zhang XW, Jin FL. The value of sTREM-1 and neutrophil surface CD64 expression in early diagnosis of sepsis. J Int Lab Med. 2012; 33(13):1590-2 (In Chinese)

67. Zhao R, Dong SM. Clinical value of serum endocan and procalcitonin in early diagnosis and prognosis of sepsis. Chin Crit Care Med. 2017;29(4): 321-6. (In Chinese). https://doi.org/10.3760/cma.j.issn.2095-4352.2017.04. 007.

68. Zhao RY, Bao YM, Yang YQ. Clinical study of serum PCT, IL-6, NT-proBNP, CTnl and DD levels in early diagnosis of emergency sepsis patients. Label Immun Clin Med. 2016;23(6):613-6 (In Chinese).

69. Zhao YZ, Li CS. Diagnostic value of biomarker combination in patients with emergency sepsis and severe sepsis. Chin Crit Care Med. 2014;26(3):153-8. (In Chinese). https://doi.org/10.3760/cma.j.issn.2095-4352.2014.03.006.

70. Wang X, Li ZY, Zeng L, Zhang AQ, Pan W, Gu W, et al. Neutrophil CD64 expression as a diagnostic marker for sepsis in adult patients: a metaanalysis. Crit Care. 2016;20(1):172. https://doi.org/10.1186/s13054-015-0972-z.

71. Li S, Huang XM, Chen ZP, Zhong HZ, Peng QL, Deng Y, et al. Neutrophil CD64 expression as a biomarker in the early diagnosis of bacterial infection: 
a meta analysis. Int J Infect Dis. 2013;17(1):e12-23. https://doi.org/10.1016/j. ijid.2012.07.017.

72. Ricarte-Bratti JP, Brizuela NY, Jaime-Albarran N, Montrull HL. IL-6, MMP 3 and prognosis in previously healthy sepsis patients. Rev Fac Cien Med Univ Nac Cordoba. 2017;74(2):99-106. https://doi.org/10.31053/1853.0605.v74.n2.14608.

73. Gür A, Oguzturk H, Köse A, Turtay MG, Ersan V, Bayindir Y, et al. Prognostic value of procalcitonin, CRP, serum amyloid A, lactate and IL-6 markers in liver transplant patients admitted to ED with suspected infection. In Vivo. 2017;31(6):1179-85. https://doi.org/10.21873/invivo.11187.

74. Guan JJ, Wang ZY, Liu XY, Jiang YJ, Gao QQ, Wu Q, et al. IL-6 and IL-10 closely correlate with bacterial bloodstream infection. Iran J Immunol. 2020; 17(3):185-203. https://doi.org/10.22034/iji.2020.87266.1793.

75. Zhao YZ, Li CS. Diagnostic value of a combination of biomarkers in patients with sepsis and severe sepsis in emergency department. Chin Crit Care Med. 2014;26(03):153-8 (In Chinese).

76. Yunus I, Fasih A, Wang YZ. The use of procalcitonin in the determination of severity of sepsis, patient outcomes and infection characteristics. PLoS One. 2018;13(11):e0206527. https://doi.org/10.1371/journal.pone.0206527.

\section{Publisher's Note}

Springer Nature remains neutral with regard to jurisdictional claims in published maps and institutional affiliations.

Ready to submit your research? Choose BMC and benefit from:

- fast, convenient online submission

- thorough peer review by experienced researchers in your field

- rapid publication on acceptance

- support for research data, including large and complex data types

- gold Open Access which fosters wider collaboration and increased citations

- maximum visibility for your research: over $100 \mathrm{M}$ website views per year

At BMC, research is always in progress.

Learn more biomedcentral.com/submissions 